\title{
A framework for design a virtual manufacturing enterprise and its implementation as a workbench
}

\author{
M. Zhou, L. Nemes
}

CSIRO Manufacturing Science and Technology

Cnr. Albert and Raglan Streets, Preston, Vic 3072, Australia

Tel. +6139662 7831, Fax. +61396627851

mwz@mlb.dmt.csiro.au,lnm@mlb.dmt.csiro.au

M. Shinonome, H. Hashimoto, A. Fuse

Toyo Engineering Corporation

8-1, Akanehama 2-chome, Narashino-shi, Chiba, Japan

Tel. +8147454 1943, Fax. +81474515487,

shin@is.,toyo-eng.co.jp, hashimoto@is.toyo-eng.co.jp,

afuse@is.toyo-eng.co.jp

P. Bernus, G. Uppington

Griffith University

Kessels Road, Nathan, Qld 4111, Australia

Tel. +6173875 5039, Fax. +6173875 5051,

bernus@cit.gu.edu.au,greg@cit.gu.edu.au

\begin{abstract}
This paper presents the design of a typical virtual enterprise (VRIDGE Inc.), as well as an integrated software environment for supporting the design, implementation and operation of the virtual enterprise (VRIDGE Workbench). The Purdue Enterprise Reference Architecture (PERA) methodology has been applied in combination with enterprise modelling tools, and extended with the STEP
\end{abstract}


methodology. This has led to the specification of information requirements of the Vridge Inc. for developing the Vridge Workbench.

We have identified three inter-related lifecycles in the design of a virtual enterprise. Several modelling tools have been evaluated and utilized. Subsequently, a reference architecture consisting of the Coordinator, the Collaborator, and the Communicator has been proposed for implementing the VRIDGE Workbench, with an aim to improve the effectiveness and efficiency of companies working in the global business environment of the $21^{\text {st }}$ century.

\section{Keywords}

IMS, Intelligent Manufacturing Systems, Globeman'21, Product Lifecycle, Global Manufacturing, Virtual Enterprise, Enterprise Integration, Enterprise Modelling Tools, STEP, CORBA, Virtual Enterprise Workbench

\section{INTRODUCTION}

In the last decade, manufacturing has become global. In order to participate in this kind of global business, manufacturing companies need to develop their ability to respond quickly to customer's requirements, cooperate closely with their global partners, and participate actively and to be commercially competitive in worldwide manufacturing projects.

The Enterprise Integration for Global Manufacturing Towards $21^{s t}$ Century (Globeman 21) project has been formed within the framework of the international research program on Intelligent Manufacturing Systems (IMS) as an international consortium to develop and demonstrate the enterprise integration tools and methods to enable a manufacturing enterprise to form a mission oriented project enterprise, i.e., a virtual enterprise, for global manufacturing business.

The Virtual and Real Information Technologies Driven Global Engineering / Enterprise (VRIDGE) demonstrator is one of the Globeman 21 projects. It aims to develop and demonstrate the life-cycle design methodologies for the virtual manufacturing enterprises and their product. The VRIDGE project envisaged a global virtual manufacturing enterprise VRIDGE Inc. that carries out the design, procurement, construction, and manufacturing of a one-of-a-kind product called XFU -- a unit of the chemical plant for producing Xylene.

A virtual enterprise is a loosely coupled enterprise which is formed by many partners (whole or parts of real companies) to fulfil a specific mission. The motivation for constructing a virtual enterprise is to enable a group of individual real enterprises to operate more efficiently and effectively as if it is a single global enterprise. As shown in Figure 1, Enterprise Integration is an enabling technology for developing a virtual enterprise from isolated enterprises. It consists of the methodologies and technologies for virtual enterprise design and operation, as well 
as the enabling information and engineering technologies for supporting the design and operation of the virtual enterprise.
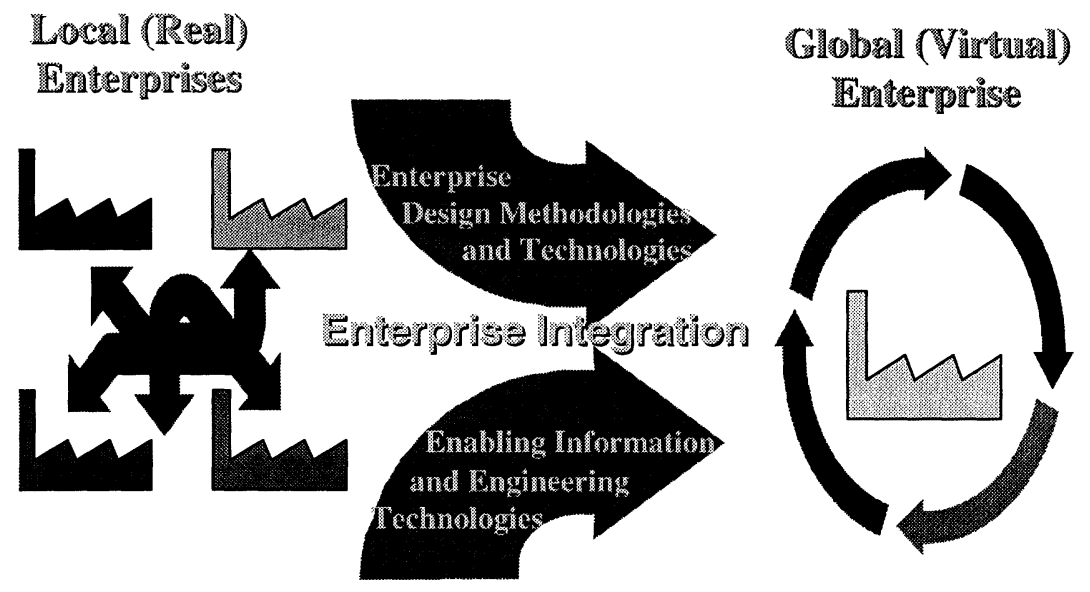

Figure 1 Enterprise Integration for Global Manufacturing

Like any real enterprise, a virtual enterprise can be formally defined in terms of an enterprise model, to describe how it is conceptually composed of and how it works. However, a virtual enterprise is to be formed quickly to provide a prompt response to customer's requests, a methodology specially for virtual enterprise modelling will therefore be essential to support the rapid business development. Furthermore, since a virtual enterprise is integrated using advanced information technology, one of the major tasks for virtual enterprise modelling will be the identification of requirements for product information access and control, as well as its enabling information infrastructure.

This paper presents our findings on design of the virtual enterprise VRIDGE Inc. and its implementation as an integrated software environment VRIDGE Workbench. The VRIDGE Inc. will be designed, implemented, and operated by the VRIDGE project. The VRIDGE Workbench will also be designed and implemented to provide a demonstration platform. The experience gained is expected to contribute to the development of a virtual enterprise design methodology, and facilitate the design and operation of future global engineering / manufacturing business processes.

\section{TOOLS AND METHODS FOR DESIGN VRIDGE INC.}

\section{The PERA Methodology}

A recently published book Architectures for Enterprise Integration ${ }^{[1]}$ presents a survey on the state-of-the-art on architectures, models, and methodologies for 
enterprise integration, including an in-depth investigation on three most sophisticated methodologies: CIMOSA, GRAI-GIM, and PERA, This project adopts the PERA methodology ${ }^{[2]}$ to describe the lifecycle of an virtual manufacturing enterprise. The PERA methodology has been successfully used by other engineering companies such as the Flour Daniel Inc., USA ${ }^{[3] \text {. }}$

The PERA methodology comprises a generic listing of those tasks which must be carried out in a manufacturing plant in order to achieve enterprise integration. The model arranges these tasks in a hierarchical functional framework to show their proper primacy and subordination to each other. It also shows the necessary data flow between these tasks. Figure 2 shows the adopted PERA methodology for the VRIDGE project.

Identification

\begin{tabular}{|c|c|c|c|}
\hline \multicolumn{4}{|c|}{ 0. Feasibility Study and Identification of the EBE } \\
\hline \multicolumn{4}{|c|}{ Concept } \\
\hline \multicolumn{4}{|c|}{ 1. Definition of Business Entity's, Mission Statement, Goals etc. } \\
\hline \multicolumn{2}{|c|}{2 VRIDGE Inc's Service Policies } & \multicolumn{2}{|c|}{ 3. VFIDGE Inc's Project Management Policies } \\
\hline \multicolumn{4}{|c|}{ Definition (Functional Pequirements) } \\
\hline \multicolumn{2}{|c|}{ 4. Requirements of VRIDCEInc's Service } & \multicolumn{2}{|c|}{ 5. Requirements of VRIDCE Inc.'s Project Management } \\
\hline \multicolumn{2}{|c|}{ 6. Functions of the VRIDCE Inc. } & \multicolumn{2}{|c|}{ 7. Project Management Functions } \\
\hline \multicolumn{2}{|c|}{$\begin{array}{l}\text { 8. Functional Requirements Specification } \\
\text { of VRDIGE Inc.'s service }\end{array}$} & \multicolumn{2}{|c|}{$\begin{array}{l}\text { 9. Functional Requirements Specification } \\
\text { of VPDIGE Inc.'s Project Managemant }\end{array}$} \\
\hline \multicolumn{4}{|c|}{ Specification (Functional Design) } \\
\hline $\begin{array}{l}\text { 10. Functional Design of VRIDCE Inc. } \\
\text { Equipment (sw/hw) }\end{array}$ & \multicolumn{2}{|c|}{$\begin{array}{l}\text { 11. Functional Design of Human Roles } \\
\text { and Organisation of VPDICE Inc. }\end{array}$} & $\begin{array}{l}\text { 12. Functional Design of VRDIGE Inc. } \\
\text { Project Management Information Systems }\end{array}$ \\
\hline \multicolumn{4}{|c|}{ Detailed Design } \\
\hline $\begin{array}{l}\text { 13. Detailed Design (or specification for } \\
\text { purchase) of VRDICE Inc. Equipment } \\
\text { (sw/hw) }\end{array}$ & \multicolumn{2}{|c|}{$\begin{array}{l}\text { 14. Detailed Design of Human } \\
\text { Tasks, Training Plan }\end{array}$} & $\begin{array}{l}\text { 15. Detailed Design (or specification for } \\
\text { purchase) of VFDIGE Inc. Project } \\
\text { Management sw/hw }\end{array}$ \\
\hline \multicolumn{4}{|c|}{ Manifestation (Build) } \\
\hline $\begin{array}{l}\text { 16. Procure or hire, implement and } \\
\text { test VRIDCE Inc. Equipment (sw/hw) }\end{array}$ & \multicolumn{2}{|c|}{$\begin{array}{l}\text { 17. Staffing, Training of } \\
\text { VDPICE Inc. personnel }\end{array}$} & $\begin{array}{l}\text { 18. Procure or hire, implement and test } \\
\text { VRDIGE Inc.'s Project MS (sw/hw) }\end{array}$ \\
\hline \multicolumn{4}{|c|}{ Operation } \\
\hline $\begin{array}{l}\text { 19. Operation of VFIDCE Inc. } \\
\text { equipment to carry out mission }\end{array}$ & $\begin{array}{l}\text { 20. Hur } \\
\text { VADCE In }\end{array}$ & $\begin{array}{l}\text { es to manage } \\
\text { ry out its mission }\end{array}$ & $\begin{array}{l}\text { 21. Operation of VPIDCE Inc.'s Project } \\
\text { Management Information System }\end{array}$ \\
\hline
\end{tabular}

Figure 2 PERA Methodology adopted in the VRIDGE Project

\section{Limitations of the PERA Methodology}

None of existing enterprise modelling architectures and methodologies provides a complete solution, although most of them are good at certain aspects of enterprise modelling. For example, the PERA methodology is good for the "master planning", and it has a detailed implementation guide. However, it does not have any tools and methods for identifying the information requirements in order to develop necessary software and hardware system to support the operation of the VRIDGE Inc. Therefore we will need to extend the methodology in order to complement its limitations. 
Existing enterprise modelling methodologies and modelling tools usually take a process oriented approach. However, in order to identify the information requirements, we also need to take an information or data oriented view of the VRIDGE Inc. One of the best available methodologies in this category is the STEP methodology [4] which has been used successfully in the development of STEP, a set of international standards for product model data exchange ${ }^{[5]}$.

Utilizing the information oriented methodology such as the STEP methodology in the analysis of product information requirement for virtual enterprise will complement and enhance the existing enterprise modelling methodologies such as the PERA to form an extended modelling methodology suitable for the virtual enterprise modelling.

\section{Extension to the PERA Methodology}

STEP is an international standard for exchanging product model data. During the more than 10 years development of STEP standard, the STEP organization has gradually formed a methodology as a means to achieve consistent and integrated Application Protocols (APs). The AP defines the context, scope, and information requirements of a designated application specific domain, and specifies the STEP constructs which satisfy these requirements.

The STEP methodology provides a guideline for an enterprise to define its specification of product information requirements. It also provides a set of modelling tools which has been tested and used during the STEP development. More importantly, it provides a set of standard resource models which will enable the enterprise to develop a product information system to process and exchange the STEP conformed product data.

We adopted the STEP methodology to specify the product information requirements for supporting the unique product lifecycle of an individual virtual enterprise, the VRIDGE Inc. We also made some necessary modifications to the STEP methodology in order to use it as an extension to the PERA methodology. The extended methodology is depicted in Figure 3. 


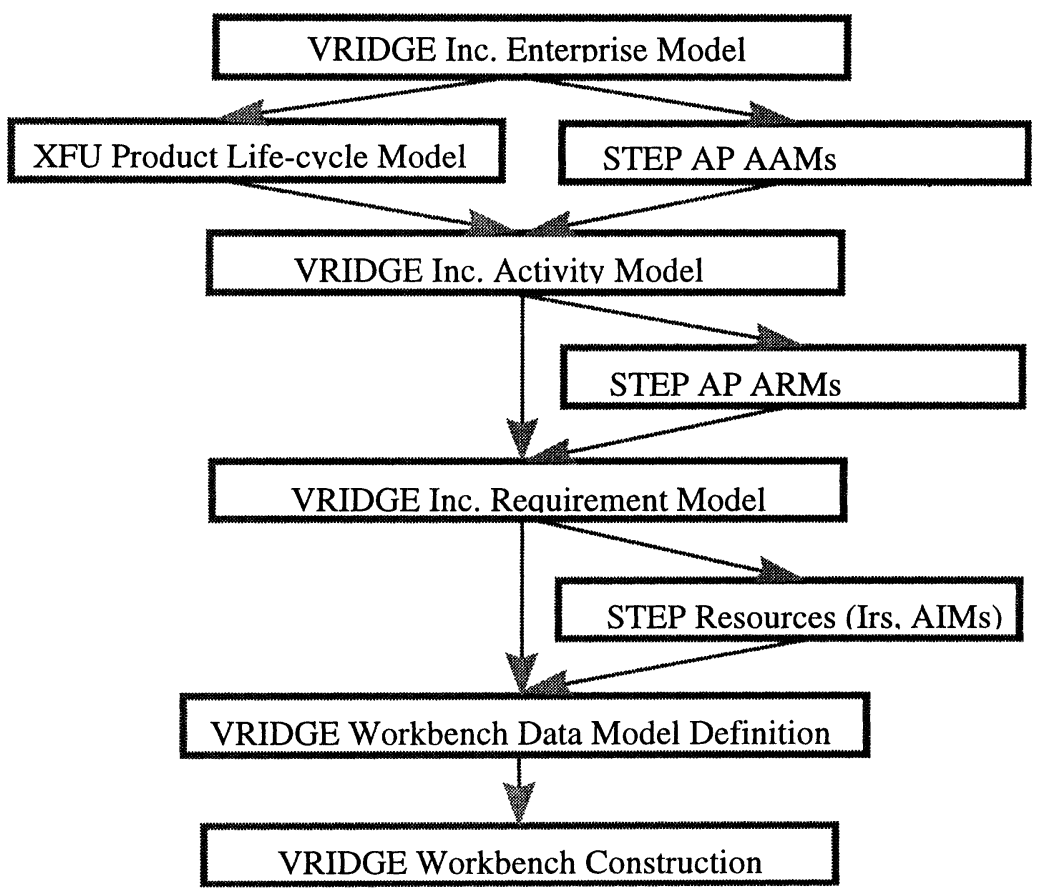

Figure 3 The Extended Methodology

With this extended methodology, we managed to bridge the gap between the modelling of a virtual enterprise and the modelling of an information system for supporting the design and operation of the virtual enterprise. As shown in Figure 3, the extended methodology uses the enterprise model to define the scope, context, and information requirements for the VRIDGE Inc. By deriving the XFU product life cycle model from the VRIDGE Inc. enterprise model, and using related STEP Application Protocols (AP) such as AP221, AP227, and AP231, we can define an activity model for the VRIDGE Inc. to describe the situation where product information needs to be shared or exchanged. This activity model can then be used to develop an information requirement model which is necessary for developing the VRIDGE Workbench to support the design, construction, and operation of the VRIDGE Inc.

\section{Tools for Modelling VRIDGE Inc.}

A formal definition in an enterprise model is needed for defining the requirements of the VRIDGE Inc. In order to develop the necessary models as shown on the PERA methodology diagram in Figure 2, we have evaluated several commercial tools available from the marketplace. A comparison of the selected modelling tools and their key features is presented in Figure 4. We concluded that no single modelling tool satisfies all our requirements at this moment, and hence we need to use a combination of these tools for different modelling objectives. 
The KBSI AIOWin, an IDEF0 ${ }^{[6]}$ based modelling tool, has been used for business process analysis and model presentation. The FirstSTEP, a user-friendly enterprise modelling tool, was selected for interactive enterprise modelling and simulation. The FirstSTEP has also been used to identify the cross company boundary information access and control requirements by using its "swimming lane" presentation. We also selected METIS as a core modelling tool and model repository because of its flexibility, an ontology based model mapping facility will be developed in the METIS environment.

\begin{tabular}{|c|c|c|c|}
\hline Tool & Company & Category & Features \\
\hline AIOWin & KBSI Inc. & $\begin{array}{l}\text { Method } \\
\text { based } \\
\text { Tool }\end{array}$ & $\begin{array}{ll}\text { - } & \text { Based on a standard method } \\
\text { - } & \text { Sophisticated GUI and easy to use } \\
\text { - } & \text { Easy to exchange the developed model }\end{array}$ \\
\hline FirstSTEP & $\begin{array}{l}\text { Interfacing } \\
\text { Technologies } \\
\text { Co. }\end{array}$ & $\begin{array}{l}\text { Model } \\
\text { based } \\
\text { Tool }\end{array}$ & $\begin{array}{l}\text { - } \quad \text { Based on a predefined enterprise model } \\
\text { Not flexible but easy to be applied to the } \\
\text { specified area }\end{array}$ \\
\hline METIS & NCR Norge AS & $\begin{array}{l}\text { Generic } \\
\text { Modelling } \\
\text { Tool }\end{array}$ & $\begin{array}{ll}\text { - } & \text { Based on a generic meta-meta-model } \\
\text { - } & \text { Flexible, can be used for many purpose } \\
\text { - } & \text { Internal DB can be accessed by API } \\
\text { WWW enhancement }\end{array}$ \\
\hline
\end{tabular}

Figure 4 A Comparison of Selected Modelling Tools

\section{THE DESIGN OF VRIDGE INC.}

\section{Identification of Related Life-cycles}

According to the PERA methodology, we need to identify the Enterprise Business Entities (EBE) which is fundamental for achieving a shared understanding of the virtual enterprise. However, we found that there are quite different views on what is the business for the VRIDGE Inc. In order to get a common understanding we categorized the business entities according to their lifecycles. We identified three lifecycles closely related to the VRIDGE Inc., as shown in Figure 5, they include:

1. The lifecycle of the VRIDGE Inc. (i.e. producer of the XFU Plant),

2. The lifecycle of the XFU Plant (i.e. product of the VRIDGE Inc.),

3. The lifecycle of Xylene as a product (i.e. product of the XFU Plant).

The identification of these three lifecycles helped us to achieve a common understanding of the business process of the VRIDGE Inc. where the product lifecycle is embedded. It is in this business process (enterprise lifecycle) where we can identify the product related activities (product lifecycle), and further identify the information access and control requirements of the product lifecycle. 


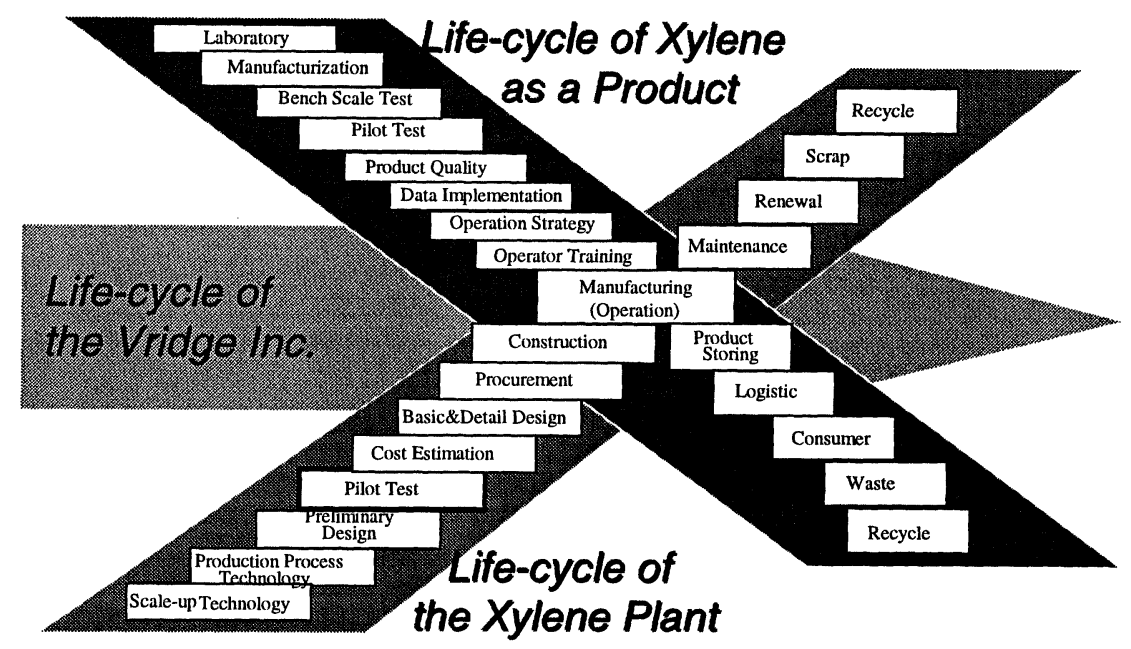

Figure 5 Lifecycles related to the VRIDGE Inc.

\section{The Concept of VRIDGE Inc.}

The identification of lifecycles also helped us to focus on the business process of the VRIDGE Inc. In order to have a better understanding of how the VRIDGE Inc would operate, we canvassed a process scenario called "Success Story" to describe the business process from Bidding to Operation and Maintenance. The story also defined the roles of business entities identified in the previous phase.

The "Success Story" has been presented to the industrial people with various backgrounds in order to attract their visions on the virtual enterprise. The scenario was refined and finally visualized using multimedia technology in order to share the understanding of the concept of VRIDGE Inc. Figure 6 shows a scene from the "Success Story". The scenario is also serving as a guideline for the further analysis and modelling of the VRIDGE Inc.

\section{The Enterprise Model of VRIDGE Inc.}

The "Success Story" is used to describe the scenario of the VRIDGE Inc. during the enterprise modelling using the FirstSTEP package. The names of major business entities, such as the names of all participating companies, personnel resources, products, activities, and major information flows, are all derived from the "Success Story". It is quite straightforward to define the higher level enterprise business process based on the textual scenario description. Figure 7 shows a snapshot of the FirstSTEP model of the VRIDGE Inc. 


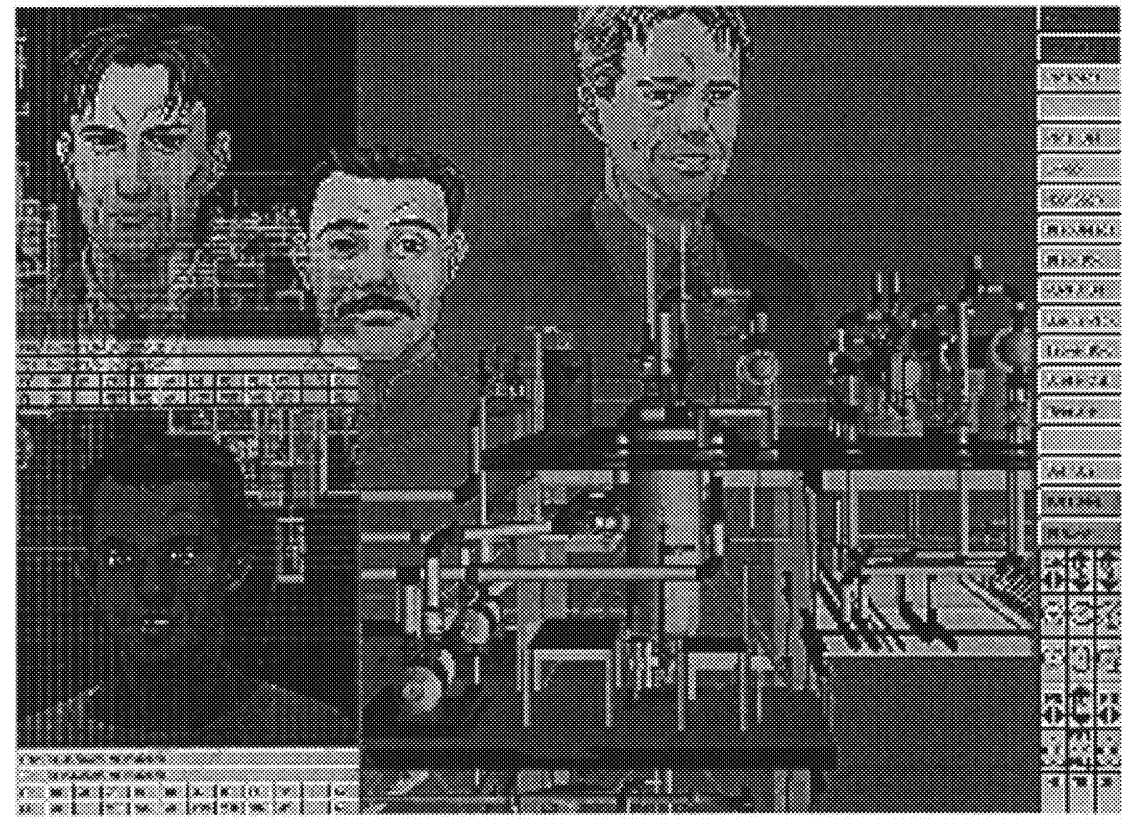

Figure 6 A Scene from the Success Story - Working with VRIDGE Workbench

\section{THE DESIGN OF VRIDGE WORKBENCH}

One of the major aims for the analysis of requirements for virtual enterprise is to develop a system to support the design, construction, and operation of the virtual enterprise. We called this integrated software environment as VRIDGE Virtual Enterprise Workbench, or VRIDGE Workbench in short. Such a workbench can be used by manufacturing companies to rapidly develop and effectively manage their global manufacturing business.

\section{Requirements for the Workbench}

Generally speaking, the workbench is expected to provide tools and methods to help the company to team up a mission oriented virtual enterprise with specialists distributed all over the world, to pull together accurate information and knowledge in a very short period to secure an order through a highly competitive bidding process, and to substantially shorten the time for passing on the information to those involved in the subsequent design, manufacturing, and maintenance phases with advanced product information access and control system. The workbench will also serve as the corporate knowledge base, the product information center, and the business contact point for the virtual enterprise. 
Scenario Organization Resources Materials Processes Activities Categories Rules

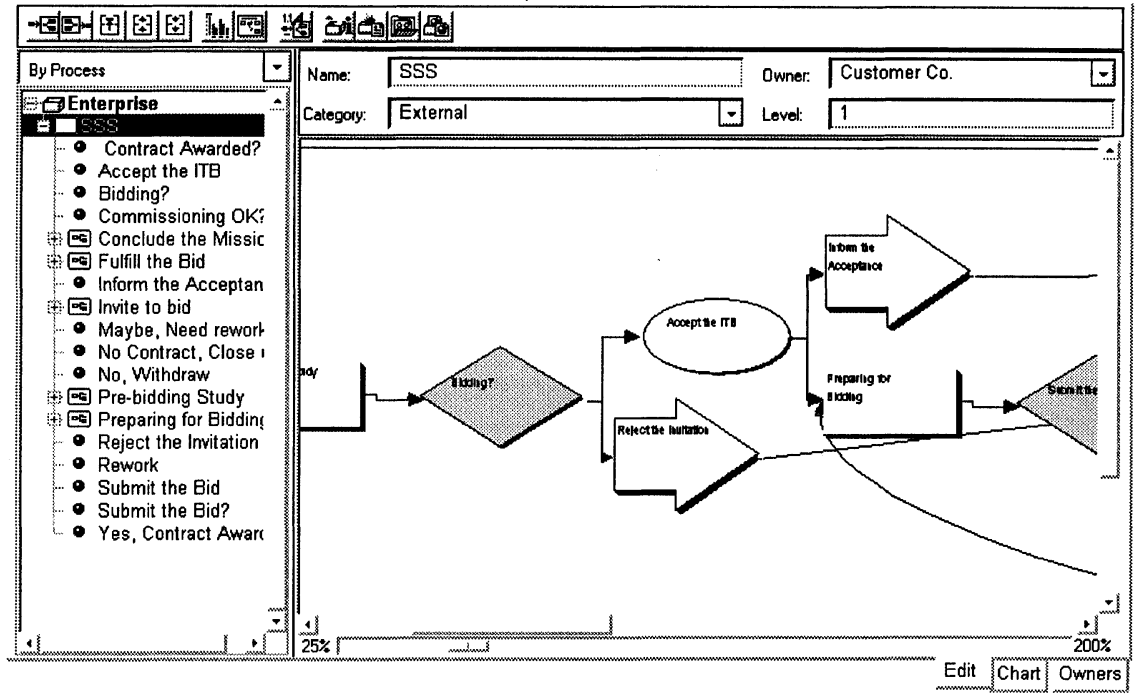

Figure 7 A Snapshot of VRIDGE Enterprise Model

\section{Architecture of the VRIDGE Workbench}

According to our analysis of the requirements for the VRIDGE Inc., we have identified that such a workbench should support the project management and coordination, the product information access and control, as well as the daily communication. An architecture has been proposed for the VRIDGE Workbench to address these identified requirements. It consists of three major functional modules: the Coordinator, the Collaborator, and the Communicator, as shown in Figure 8.

\section{Functional Modules of the Workbench}

The Coordinator, Collaborator, and Communicator together form an integrated workbench for supporting the design, construction, and operation of the VRIDGE Inc. The Coordinator will support the virtual enterprise design and operation; the Collaborator will support the product development and assist engineers and managers to control product information; and the Communicator will serve as a communication center for all engineers and managers within a local company and among globally distributed partners of the virtual enterprise. 


\section{Vridge Virtual Enterprise Workbench}

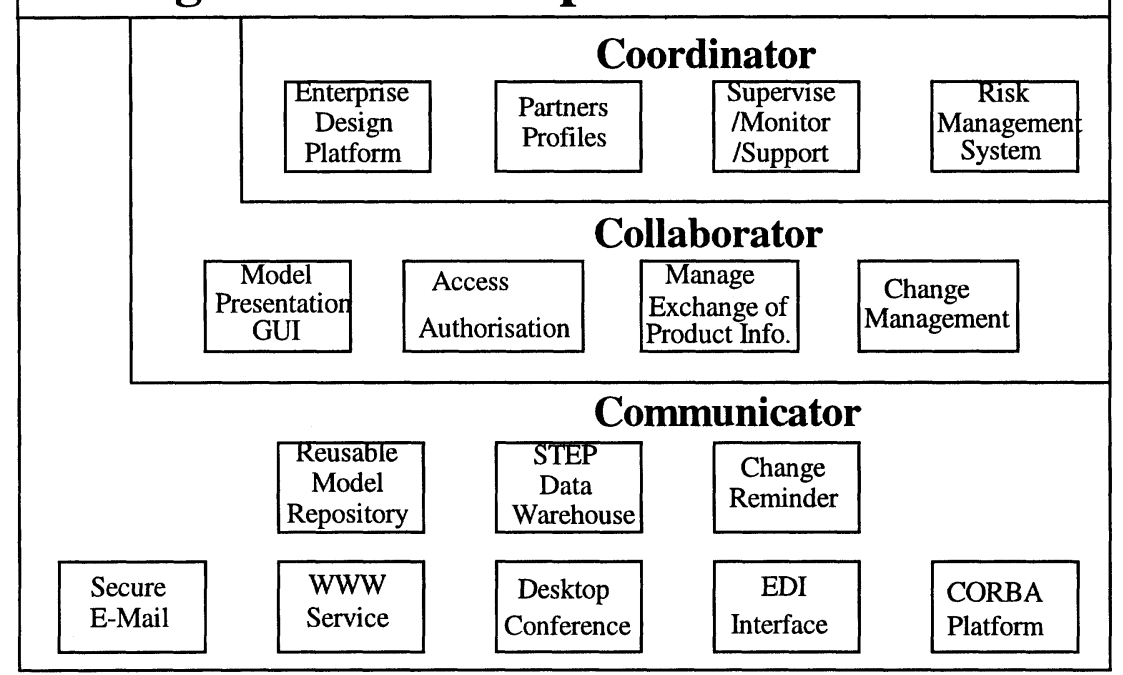

Figure 8 Architecture of VRIDGE Workbench

\section{The Coordinator}

The Coordinator will consist of four major functions:

1. The Enterprise Design Platform for analyzing, modelling, and simulating the virtual enterprise business process and information flow. This sub-module will be implemented by integrating existing modelling packages such as Metis. Necessary user- and data- interfaces will be implemented, and the extended enterprise methodology will be implemented into a multimedia tutorial system and an on-line help system to provide guidance to the virtual enterprise design.

2. The Partner Profile System for managing all the necessary information about potential partners who may participate in the virtual enterprise. It will also manage the protocols for coordinating the business processes, such as Request for Change, Design Review, etc.

3. The Project Supervising/Monitoring/Supporting System for project management and coordination. It will support the operation of the virtual enterprise and provide a transparent interface between partners.

4. The Risk Management System for controlling potential risks involved in the operation of the virtual enterprise. The commercial risk management tools will be incorporated into the workbench. 


\section{The Collaborator}

The Collaborator will also consist of four major functions:

1. The Change Management System for issuing and approving the Requests for Change during the product development. The system will then select a proper protocol for change management through the Partner Profile System, and send out the request through facilities provided by the Communicator, such as Secure E-mail or CORBA.

2. The Product Information Exchange Management System for deriving or converting the product information from one format to another. STEP based interfaces will be used to access and dispatch the product data stored in the STEP Data Warehouse.

3. The Access Authorization Management System for information access control. The system will manage everyone's access right to the confidential information such as the product data according to the advice from Partner Profiles System.

4. The Model Presentation GUI for visualizing various models. The GUI will provide a set of interfaces for presenting the enterprise models, product models, as well as 2D and 3D product model data.

\section{The Communicator}

The Communicator will provide general communication tools which will be used by human users and other functional modules of the Coordinator and Collaborator. The EDI Interface and CORBA platform provide necessary facilities for Internet based computing and communication. The Secure E-mail system provides a reliable method for delivering confidential information such as the bid. The WWW Service provides a versatile platform for on-line discussion, design review, as well as information searching and browsing. The Change Reminder sends immediate alarm to the related people whenever a change is registered. The Desktop Video Conference System provides a real-time meeting platform over the network serving as an alternative to the face-to-face meeting.

The Communicator manages two databases for the workbench. The STEP Data Warehouse manages all STEP confirming product information which is created, modified, and used during the operation of the VRIDGE Inc., while the Reusable Model Repository manages all kinds of reusable models which are created before or during the design and operation of the VRIDGE Inc.

\section{Implementation}

The proposed VRIDGE Workbench will be implemented in two phases. A proofof-concept workbench is currently being implemented, and expected to be finished by the end of 1998. This proof-of-concept implementation will then be used for 
experiment and gathering feedback from users. After necessary refinement, the full scale workbench will then be implemented and used to demonstrate the design, construction, and the operation of the VRIDGE Inc.

\section{ACKNOWLEDGE}

Part of the research and development tasks have been conducted by Dr. John Mo, Dr. Ambalavanar Tharumarajah, Mr. Michael Kovacek and Ms. Angela Williams of CSIRO. Special thanks also go to Mr. Tetsuya Miyagawa of Takenaka Corporation, Mr. Michiaki Yamagata of Yokogawa Electric Corporation and Mr. Frank Lillehagen and Ms. Sobah Abbas Petersen of NCR Norge.

\section{REFERENCE}

[1] Bernus, P., Nemes, L., Williams T.J. “Architectures for Enterprise Integration", Chapman and Hall, London, 1996

[2] Williams, T.J. "The Purdue Enterprise Reference Architecture (PERA)", Computers in Industry, Elsevier, 24(2-3) 1994

[3] Bernus, P., Nemes, L. "Modelling and Methodologies for Enterprise Integration", Chapman and Hall, London, 1996

[4] M. Palmer, "Guidelines for the development and approval of STEP application protocols", Technical Report ISO TC184/SC4/WG4/N25, Sept. 1991

[5] ISO, "Industrial automation systems and integration - Product data representation and exchange", ISO 10303, 1994

[6] NIST, "Integration Definition for Function Modelling (IDEF0)", Federal Information Processing Standards Publications (FIPS PUBS) 184, 1993

\section{BIOGRAPHY}

Dr. Mingwei Zhou is an active researcher in the VRIDGE Demonstrator of the Globeman 21 Project, a consortium under the international IMS Program. He has over 10 years experience in research and development on computer applications in manufacturing industries. Currently, he is a Senior Research Scientist in CSIRO Manufacturing Science and Technology, working on the tools and methods for the design and implementation of virtual manufacturing enterprises. 